\title{
A Diverse Specialty: What Students Teach Us About Neurology and "Neurophobia"
}

\author{
Fraser G. A. Moore (1D
}

\begin{abstract}
Objective: To explore what elective students learn about the specialty of Neurology. Methods: A prospective qualitative study using pre- and post-elective written questionnaires. Results: Analysis concentrated on three main themes: What did students learn about the specialty of Neurology? What would they change about their experience? Did their opinions change? Major findings were (i) pre- and post-elective the most frequent response for "what is the best thing about Neurology?" was the "process of localization" and (ii) post-elective students were less likely to cite the challenge or problem-solving aspect of Neurology as the best thing while more emphasized the importance of the physical exam and the variety of cases. (iii) Students were most surprised by the scope of neurological practice. (iv) They would diversify the setting of their elective to include less time spent in the emergency room and more time in clinic. (v) The perception of Neurology as a specialty in which patients have a poor prognosis was the opinion that changed the most. Conclusions: Showcasing the diversity of cases and careers in Neurology may be a useful strategy to increase interest in the specialty and reduce neurophobia. Lectures or small groups early in medical school should concentrate on clear examples of common neurological conditions and emphasize the role of general neurologists and subspecialists involved in patient care. Whenever possible students should rotate through different clinics and not concentrate exclusively on emergency room and in-patient cases.
\end{abstract}

RÉSUMÉ : Une spécialité diversifiée : ce que les étudiants peuvent nous enseigner au sujet de la neurologie et de la « neurophobie ». Objectif : Explorer ce que des étudiants ont appris au sujet de la neurologie dans le cadre de cours optionnels portant sur cette spécialité. Méthodes : Une étude prospective qualitative faisant appel à des questionnaires remis avant le début et à la fin de ces cours. Résultats : Notre analyse a mis l'accent sur trois principaux aspects : premièrement, ce que les étudiants ont appris à propos de la neurologie ; deuxièmement, ce qu'ils changeraient au sujet de leur expérience ; enfin, dans quelle mesure leurs opinions ont changé. Nos principales constations ont été les suivantes : (i) la réponse la plus fréquente donnée à la question «Qu'est-ce que le domaine de la neurologie a de plus intéressant ? » a été le «processus de localisation », et ce, que ce soit avant le début des cours ou une fois ces derniers terminés ; (ii) les étudiants ayant répondu à un questionnaire une fois leur cours terminé étaient moins susceptibles d'évoquer comme aspect le plus intéressant de la neurologie le fait de faire face à un défi ou la résolution de problèmes tandis qu'un plus grand nombre d'entre eux a mis en relief l'importance d'effectuer un examen physique et la variété des cas ; (iii) les étudiants se sont dits très surpris de l'étendue de la pratique en neurologie ; (iv) ils seraient aussi enclins à diversifier le cadre de ces cours optionnels afin de passer moins de temps dans des salles d'urgence et plus de temps dans un contexte clinique ; (v) enfin, la perception suivant laquelle la neurologie est une spécialité dont les patients ne peuvent escompter que de mauvais pronostics est celle qui a changé le plus. Conclusions : Il se peut donc que le fait de mettre en évidence la diversité des cas et des possibilités de carrière en neurologie soit une stratégie utile permettant d'accroître l'intérêt à l'égard de cette spécialité et de réduire la «neurophobie ». Des cours et du contenu abordé en petits groupes au début de la formation en médecine devraient ainsi mettre l'accent sur des exemples clairs d'affections neurologiques courantes et insister sur le rôle des neurologues généraux et des sous-spécialistes impliqués dans les soins donnés aux patients. Chaque fois que c'est possible, les étudiants devraient à tour de rôle visiter diverses cliniques et ne pas se concentrer exclusivement sur les urgences et sur les cas de patients hospitalisés.

Keywords: Education, Neurology, Neurophobia

doi:10.1017/cjn.2020.102

Can J Neurol Sci. 2020; 47: 675-680

The term "neurophobia" was coined years ago to describe a fear of Neurology on the part of medical students. ${ }^{1,2}$ Neurophobia continues to be prevalent today. ${ }^{3-5}$ Some authors have noted the gap between this perception of Neurology and the "neurophilia" that exists in society with increasing interest in and awareness of neurological disorders such as stroke and multiple sclerosis. ${ }^{6}$ As neurologists, it would be ideal if we could take advantage of "neurophilia" to promote our specialty among students and showcase its many strengths. ${ }^{7}$
One practical step would be to have a better understanding of the experience of medical students completing electives in Neurology. What is their opinion of the specialty before they begin their elective? What do they learn during their elective? Do their opinions change? The purpose of this study was to understand what elective students can teach us about our specialty that could then inform teaching of all medical students, with the ultimate goal of reducing neurophobia and attracting more students to Neurology.

From the Department of Neurology, McGill University, Montréal, Québec, Canada (FGAM)

Received March 19, 2020. Final Revisions Submitted May 19, 2020. Date of Acceptance May 19, 2020.

Correspondence to: Dr. Fraser Moore, 3755 Côte-Ste-Catherine E-005, Montréal, Québec, H3T 1E2, Canada. Email: fraser.moore@mcgill.ca 
Table 1. Demographic characteristics of students completing the pre-elective questionnaire (p-values given from one-way ANOVA)

\begin{tabular}{|c|c|c|c|c|c|}
\hline & $\begin{array}{l}\text { McGill } \\
(n=15) \\
\end{array}$ & $\begin{array}{c}\text { Canadian* } \\
(n=11)\end{array}$ & $\begin{array}{c}\text { International }^{* *} \\
(\boldsymbol{n}=\mathbf{1 0})\end{array}$ & $\begin{array}{c}\text { Total } \\
(n=36)\end{array}$ & ANOVA \\
\hline Mean age (range) & $24(21-31)$ & $23(21-30)$ & $26(23-32)$ & 24 & \\
\hline$\%$ female & 67 & 64 & 70 & 67 & \\
\hline$\%$ with university degree & 21 & 82 & 40 & 44 & $p=0.005$ \\
\hline Final year of training $(\#)^{* * *}$ & 64 & 64 & 80 & 71 & \\
\hline$\%$ completed all core clerkship rotations & 60 & 73 & 70 & 67 & \\
\hline$\%$ with prior Neurology electives & 20 & 64 & 70 & 47 & $p=0.197$ \\
\hline Median \# (range) of prior electives & $0(0-3)$ & $2(0-4)$ & $1(0-2)$ & $0(0-4)$ & \\
\hline Median weeks (range) of prior electives & $0(0-9)$ & $2(0-8)$ & $0(0-12)$ & $0(0-12)$ & $p=0.484$ \\
\hline$\%$ with prior Neuroscience research & 47 & 55 & 20 & 42 & \\
\hline $\begin{array}{l}\text { Duration of current elective: } \\
2 \text { weeks } \\
3 \text { weeks } \\
4 \text { weeks }\end{array}$ & 1014 & 613 & 0010 & 7127 & $\mathrm{p}<0.0001$ \\
\hline
\end{tabular}

*Memorial, UBC, Ottawa, Calgary, Toronto (2), Dalhousie, McMaster, Queen's, Montreal, Sherbrooke.

**Australia (2), Argentina, Netherlands (2), Hong Kong, France, Austria, Saudi Arabia, Jordan.

***Year 3 of a 3-year program, year 4 of a 4-year program, or year 6 of a 6-year (international) program.

\section{Methods}

This study was conducted between September 2011 and March 2015 at the Jewish General Hospital (JGH) in Montreal, a 637-bed tertiary care teaching hospital of McGill University. Medical students who agreed to participate in the study signed a consent form and completed a written pre-elective questionnaire (Appendix 1) that included demographic questions and three specific questions with choices asking why they chose to do the elective, what they were most interested in learning about, and if they had a preference where they saw patients. Students had the option of adding other options. There were also three open-ended questions (without any choices provided) asking about the duration of the elective and what they thought were the best and worst things about Neurology. Following their elective, students were asked to complete a written post-elective questionnaire (Appendix 2) that included 10 open-ended questions.

A consecutive series of students were asked to participate. They worked on the Neurology consultation service, which sees an average of 8-10 consults per day in the emergency room, intensive care units, and on in-patient floors. The service typically includes 1-2 Neurology residents and 1-2 off-service residents from other specialties. Attending staff changes weekly. An average student personally sees one new neurological consultation per day, with good students potentially seeing two or more. Students were not assigned to an in-patient clinical teaching unit or out-patient clinics.

Quantitative data were analyzed by descriptive statistics where appropriate. Qualitative data were analyzed using principles of thematic analysis consistent with qualitative description. ${ }^{8}$ Responses to a given question were coded and then organized into themes. Questionnaires were then reviewed again to ensure both that the themes identified accurately reflected the data and that no important ideas had been excluded.
The study was approved by the Research Ethics Committee of the JGH.

\section{Results}

Student demographics and their reasons for doing an elective are presented in the first two sections. The remaining results are grouped into three main themes: What did students learn about the specialty of Neurology? What would they change about their experience? Did their opinions change?

\section{Demographics}

Demographics are shown in Table 1. Fifty-five students completed an elective during the study period. Thirty-six students agreed to participate and completed the pre-elective questionnaire. Eighteen students did not complete the pre-elective questionnaire because the author was unavailable to meet with them at the start of the elective to explain the study and obtain consent. Only one student declined to participate.

Students from McGill were less likely to have completed prior Neurology electives (Table 1) although this was not statistically significant. Differences in weeks of prior electives in Neurology also did not reach statistical significance. Students from other Canadian medical schools were more likely than McGill or International students to have a university degree and to be completing electives of less than 4 weeks duration. Twenty-three students completed the post-elective questionnaire (Appendix 2).

\section{Why did students choose to do an elective?}

Students were asked to rank their reasons for choosing the elective from a list of seven choices (Appendix 1). They could also write in additional reason(s). The options that students ranked first were learning about the neurological examination 
Table 2. Student opinions regarding "the best thing about Neurology" before and after their elective. Written responses of individual students were grouped into themes. Results are given as the number of responses (percentages are rounded up)

\begin{tabular}{|c|c|c|}
\hline Response & Before $(n=38 *)$ & After $(n=22)$ \\
\hline Localization & $\begin{array}{c}13 \\
(34 \%)\end{array}$ & $\begin{array}{c}8 \\
(36 \%)\end{array}$ \\
\hline Challenging/makes you think & $\begin{array}{c}5 \\
(13 \%)\end{array}$ & 0 \\
\hline Fascinating & $\begin{array}{c}4 \\
(11 \%)\end{array}$ & $\begin{array}{c}1 \\
(5 \%)\end{array}$ \\
\hline Systematic approach to problem solving & $\begin{array}{c}4 \\
(11 \%)\end{array}$ & 0 \\
\hline Importance of the physical exam & $\begin{array}{c}4 \\
(11 \%)\end{array}$ & $\begin{array}{c}5 \\
(23 \%)\end{array}$ \\
\hline Variety of cases & $\begin{array}{c}3 \\
(8 \%)\end{array}$ & $\begin{array}{c}5 \\
(23 \%)\end{array}$ \\
\hline Whole body involvement & $\begin{array}{c}2 \\
(5 \%)\end{array}$ & 0 \\
\hline Amount of knowledge & $\begin{array}{c}1 \\
(3 \%)\end{array}$ & 0 \\
\hline Interacting with patients & $\begin{array}{c}1 \\
(3 \%)\end{array}$ & $\begin{array}{c}2 \\
(9 \%)\end{array}$ \\
\hline Opportunities for research & $\begin{array}{c}1 \\
(3 \%)\end{array}$ & 0 \\
\hline New developments & 0 & $\begin{array}{c}1 \\
(5 \%)\end{array}$ \\
\hline
\end{tabular}

*Two students gave two responses each and both were included (thus, there are 38 total responses from 36 students).

$(n=9)$, obtaining additional teaching in Neurology $(n=10)$, learning more about Neurology as a career $(n=6)$, confirming an interest in Neurology $(n=4)$, learning about Neurological problems relevant to other specialties $(n=1)$, obtaining letter(s) of reference $(n=3)$, learning about the McGill program $(n=2)$, and it was a requirement $(n=1)$. Students gave a mean number of three choices.

As stated above, the remaining results are grouped into three themes.

\section{What did students learn about the specialty of Neurology?}

On the post-elective questionnaire students were asked "what was the most important thing that you learned during the rotation?" This was an open-ended question, and some students provided more than one answer. A total of 28 different responses were received from 23 students. Students most frequently cited some aspect of the neurological exam including how to perform the exam $(n=11)$, the importance of a focussed exam $(n=3)$, exposure to examination findings $(n=1)$, and correlating the exam with imaging $(n=1)$. Other responses included an approach to neurological problems $(n=5)$, history-taking $(n=4)$, how to think like a neurologist $(n=1)$, how to formulate a differential diagnosis while taking the history/performing the exam $(n=1)$, and thinking about physiology in clinical practice $(n=1)$. Students who cited the neurological exam were equally likely to have completed core clerkship rotations as those who gave other responses.
Table 3. Student opinions regarding "the worst thing about Neurology" before and after their elective. Written responses of individual students were grouped into themes. Results are given as the number of responses (percentages are rounded up)

\begin{tabular}{|c|c|c|}
\hline Response & Before $(n=38)$ & After $(n=22)$ \\
\hline Lack of treatments/ poor prognosis & $\begin{array}{c}16 \\
(42 \%)\end{array}$ & $\begin{array}{c}6 \\
(27 \%)\end{array}$ \\
\hline $\begin{array}{l}\text { Lack of a clear diagnosis for some } \\
\text { symptoms }\end{array}$ & $\begin{array}{c}4 \\
(11 \%)\end{array}$ & $\begin{array}{c}1 \\
(5 \%)\end{array}$ \\
\hline Not many procedures & $\begin{array}{c}3 \\
(8 \%)\end{array}$ & \\
\hline Too many psychiatric complaints & $\begin{array}{c}2 \\
(5 \%)\end{array}$ & \\
\hline Difficult anatomy & $\begin{array}{c}2 \\
(5 \%)\end{array}$ & $\begin{array}{c}1 \\
(5 \%)\end{array}$ \\
\hline Nothing & $\begin{array}{c}2 \\
(5 \%)\end{array}$ & \\
\hline $\begin{array}{l}\text { Reliance on patients for parts of physical } \\
\text { exam (e.g. sensory) }\end{array}$ & $\begin{array}{c}2 \\
(5 \%)\end{array}$ & $\begin{array}{c}2 \\
(9 \%)\end{array}$ \\
\hline $\begin{array}{l}\text { The stigma that there are no available } \\
\text { treatments }\end{array}$ & $\begin{array}{c}1 \\
(3 \%)\end{array}$ & \\
\hline Time needed to complete consults & $\begin{array}{c}1 \\
(3 \%)\end{array}$ & \\
\hline The dissociation from psychiatry & $\begin{array}{c}1 \\
(3 \%)\end{array}$ & $\begin{array}{c}1 \\
(5 \%)\end{array}$ \\
\hline Giving bad news & $\begin{array}{c}1 \\
(3 \%)\end{array}$ & $\begin{array}{c}1 \\
(5 \%)\end{array}$ \\
\hline Elderly patient population & $\begin{array}{c}1 \\
(3 \%)\end{array}$ & \\
\hline Complexity of the neurological exam & $\begin{array}{c}1 \\
(3 \%)\end{array}$ & \\
\hline $\begin{array}{l}\text { Difficulty explaining the neurological exam } \\
\text { to patients }\end{array}$ & $\begin{array}{c}1 \\
(3 \%)\end{array}$ & \\
\hline $\begin{array}{l}\text { Too many patients without neurological } \\
\text { disease }\end{array}$ & & $\begin{array}{c}4 \\
(18 \%)\end{array}$ \\
\hline Imprecise nature of diagnosis/treatment & & $\begin{array}{c}2 \\
(9 \%)\end{array}$ \\
\hline Limited academic jobs & & $\begin{array}{c}1 \\
(5 \%)\end{array}$ \\
\hline No answer & & $\begin{array}{c}3 \\
(14 \%)\end{array}$ \\
\hline
\end{tabular}

When asked the open-ended question "what did you learn that surprised you?," the most common responses were the scope of neurological practice $(n=5)$, the fact that Neurology was not as difficult as expected $(n=4)$, and the subtlety of some neurological presentations $(n=3)$. Things that surprised students about the scope of neurological practice were "how vast the field is"; "how common young patients are"; the variety of peripheral nervous system pathology including diseases of muscle and the autonomic nervous system; that the specialty is "more hands on than expected" (with the example of carotid ultrasound); and differences between centers (with the example of approach to code strokes). 
When asked the open-ended question, "what did you learn about the field of Neurology (as a career)?" there were seven students who mentioned the different career paths available (such as academic vs. community practice), followed by four who emphasized the diversity of cases and three who said that localizing lesions is hard and fun.

\section{What would students change about their experience?}

When asked this open-ended question on the post-elective questionnaire, seven students would not change anything. Six would have preferred more structured teaching, either lectures or scheduled teaching sessions covering an approach to specific topics relevant for students (such as stroke, headache, or seizures). Five students would have preferred to experience other practice settings such as out-patient clinics. Students had been asked pre-elective where they preferred to see patients and were provided with multiple different choices; the majority chose the emergency room as the answer $(n=27)$.

Students were asked following the elective whether the duration was appropriate, or whether a longer or shorter elective would have better suited their needs. Seven students felt the duration had been too short while 13 felt it was appropriate. This was an open-ended question; students were not asked to choose a specific duration. The subgroup of students completing a 2-week elective and the subgroup intending to apply to Neurology residency programs did not differ in their response compared to other students (i.e. they were not more likely to say that their elective should have been longer). Four students who completed a 2-week elective did specifically state that they chose this duration because they needed to see as many programs as possible.

\section{Did student's opinions about Neurology change?}

Students were asked on the pre- and post-elective questionnaires to provide written comments regarding the best and worst thing about Neurology (Tables 2 and 3).

Thirteen of 21 students had a post-elective response for what is best about Neurology that was grouped into a different theme than their pre-elective response. In both pre- and post-elective, the largest category of response for the best thing was the "process of localization." Post-elective students were less likely to cite the challenge or problem-solving aspect of neurology while relatively more emphasized the importance of the physical exam and the variety of cases.

Nine of 21 students had a post-elective response for what is worst about Neurology that was grouped into a different theme than their pre-elective response. A large majority felt the worst thing about neurology pre-elective was that treatment options are often limited and/or prognosis is poor (42\%). Post-elective students were less likely to cite this, while they were more likely to cite the number of cases without a neurological disease or the "imprecise" nature of diagnosis. Of 16 students who originally identified limited treatment/poor prognosis as the worst thing, only two had done prior electives in Neurology (compared to 15 of the 20 students who identified other features). One additional student said that the worst thing was not that there are no available treatments but rather the fact that this stigma about Neurology even exists.
A change in theme pre- versus post-elective for what is worst about Neurology was more likely for students with prior electives and those planning to apply to Neurology residency; this association was not seen for what is best about Neurology. Only five of the 21 students completed a 2 -week elective (the rest completed 4-week electives) and so any possible effect of elective duration could not be studied.

Students were also asked on the post-elective questionnaire whether their perception of the specialty of Neurology had changed and to explain their answer. Seventeen of 21 students said their perception had changed and they provided a total of 18 reasons why. The largest category was a new appreciation for the variety and diversity of cases in Neurology $(n=6)$. Three students cited a greater availability of treatment than expected, and two mentioned the clinical skill of neurologists. The seven other reasons were a greater awareness of career paths, greater integration with neuroscience, greater workload than expected, requirement of a broad knowledge base, a greater age range of patients than expected, greater collaboration between professionals than expected, and the negative perception of consults requested for vague or "non-specific" symptoms such as numbness. This final reason was given by a student who did not intend to pursue Neurology as a career. They worried that in the future they might feel reluctant to request a Neurology consult for a patient with such symptoms because it might be perceived as a poor or unnecessary consult.

Eleven of 23 students reported post-elective that they were more interested or newly interested in Neurology as a specialty. Comparing pre- and post-elective questionnaires, only 8 of 23 students had changed their mind about applying to Neurology residency.

\section{Discussion}

A number of the themes that emerged from this study suggest strategies that could reduce neurophobia among medical students and increase interest in the specialty of Neurology. Elective students were surprised by the scope of neurological practice, including the diversity of cases and range of subspecialties. Although it has been previously suggested that non-neurologists may be unaware of this diversity, ${ }^{7}$ it is perhaps surprising that elective students were unaware of it. Showcasing this diversity to all students earlier in medical school might increase interest in the specialty.

It is possible that too great an emphasis on case diversity could be perceived as overwhelming by some students and actually increases neurophobia. An important area for future study would be to determine how to present this diversity in a positive light. One strategy could be to emphasize the growth in subspecialty training in Neurology. ${ }^{9}$ This allows for consultation and teamwork between colleagues; a given neurologist may not have expertise in every area of Neurology but is still able to localize and diagnose neurological problems, relying on help from specialty colleagues when needed.

If case diversity is a positive element that could reduce neurophobia, then would emphasizing the intellectually challenging aspect of Neurology also attract students? "The process of localization" was most frequently identified as the best thing about neurology, both pre- and post-elective. However, 
post-elective students as a group were also less likely to cite the challenging, fascinating, or problem-solving aspect of neurology as the best thing. Relatively more emphasized the importance of the physical exam and the variety of cases. Case diversity may therefore be perceived as a positive aspect separate from the intellectual challenge. Alternatively, students may have more frequently cited the neurological exam and case diversity because these are observable. In contrast, clinical reasoning is not readily observable unless a preceptor explains their thought process explicitly.

Rather than emphasizing the intellectual challenge of Neurology to all students, a better strategy may be to capitalize on their willingness to learn ${ }^{4}$ by increasing the practical experience they have in medical school with neurological cases. ${ }^{3,6}$ Some students here were surprised that Neurology was not as difficult as they expected. Helping all students to see Neurology as a challenge, they can personally meet by giving them more practical experience may thus be more important. How to most effectively do this could be a topic for future research.

Some previous authors have discussed the importance of focussing on common neurological conditions, rather than interesting but rare cases that are often emphasized at rounds and in the literature. ${ }^{2,5,7}$ Students here said that they would change or diversify the setting of their elective to include less time spent in the emergency room and more time in clinic. While it is simplistic to suggest that emergency room (ER) cases are "complex" and those seen in out-patient clinics are "common," it may be broadly true that ER cases are more likely to have multiple symptoms and complicated past medical histories, while those seen in clinics are more likely to have single problems. It is also likely that the clinic setting provides a more controlled and less time-sensitive setting for medical students to see patients. If showcasing the diversity of the specialty is a useful strategy to reduce neurophobia, then it may be best accomplished by combining experience in the ER with common neurological conditions in out-patient clinics.

Neurology is commonly perceived as a specialty in which patients have a poor prognosis and treatment options are limited. Although some have argued this reputation is "behind us,"7 it was still mentioned by many students in this study. It was more common among students with fewer prior electives in Neurology and was also the opinion that changed the most, suggesting it is not hard to change this opinion about the specialty. Directly emphasizing recent treatment advances in Neurology could allow students to see Neurology as a rapidly advancing field. This in turn could result in a greater willingness to learn more about Neurology and reduce neurophobia. In keeping with the idea of focussing on common problems, it may be important to present treatment advances in a general way rather than covering them in detail.

One outstanding question is whether changes in opinion require electives of a certain duration. A more diverse experience might be obtained with longer electives, but students here were mixed when asked if the duration of their elective was appropriate. A more important question may be whether changing opinions requires an immersive experience such as an elective at all, or if focussed classroom teaching alone could have the same effect. Although increasing student confidence may require clinical experience, as already discussed, perhaps classroom teaching alone is sufficient to change student opinions. This is another question for future research.
A related question for future research is whether changes in opinion are transient.

Some authors have argued that any decrease in neurophobia is unlikely to persist into clerkship. ${ }^{3}$ Others have shown that increased enthusiasm for Neurology did not translate into matching to residency. ${ }^{10}$ In the future, it would be important to specifically assess individual students' opinions over time ${ }^{4}$ as they progress through clerkship and residency.

This study does have limitations. A relatively small number of students from a single center were included. However, students were asked to respond to many open-ended questions, allowing a more thorough understanding of their views. They were also a diverse group in terms of their stage of training and the location of their medical school, which makes the results more widely relevant. A second weakness is that this study only included students who had chosen to do an elective in Neurology. These students already had some interest in the specialty and their opinions may thus differ from other students. However, the motivation of the students in this study for doing their elective varied. Some were interested in pursuing Neurology as a career, but others had different reasons such as improving their examination skills, presumably because they felt less comfortable with Neurology. Some of the results, such as being surprised by the case diversity or changing their opinions about the lack of treatments, also suggest that many of the students were relatively naive about Neurology and may be representative of all medical students. Comparing the results to a sample of non-elective medical students could be another area for future research.

In conclusion, the results suggest that elective students in this study were receptive, observant, and often changed their opinions about Neurology. Showcasing the diversity of cases and careers in Neurology may be a useful strategy to increase interest in the specialty and reduce neurophobia. This could be done early in medical school in lectures or small groups by concentrating on clear examples of common neurological conditions and emphasizing how both general neurologists and subspecialists are involved in the care of these patients. If students have the opportunity to work in the clinical setting later in medical school an effort could once again be made to emphasize the diversity of the specialty by allowing students to rotate through different clinics, and not concentrating exclusively on emergency room and in-patient cases. Looking for other strategies to present the diversity of the specialty in a positive light and to increase students' practical experience in Neurology are important areas for future research.

\section{ACKNOWLEDGEMENT}

The author would like to thank Dr. Aleksandra Mineyko for her feedback and encouragement regarding the poster version of this manuscript and Dr. Stuart Lubarsky for his critical review of the written manuscript.

\section{Disclosure}

Dr. Moore reports personal fees from Novartis Pharma Canada Inc, outside the submitted work, and he is currently the McGill Adult Neurology Residency Program Director. At the time of the study, he was serving on the McGill Residency Training Program Committee. 


\section{STATEMENT OF AUTHORSHIP}

FM designed and carried out this study, analyzed the data, and wrote the manuscript.

\section{SUPPLEMENTARY MATERIAL}

To view supplementary material for this article, please visit https://doi.org/10.1017/cjn.2020.102.

\section{REFERENCES}

1. Jozefowicz RF. Neurophobia: The fear of Neurology among medical students. Arch Neurol. 1994; 51:328.

2. Ridsdale L, Massey R, Clark L. Preventing neurophobia in medical students, and so future doctors. Pract Neurol. 2007; 7: 116-23.

3. Fantaneanu TA, Moreau K, Eady K, Clarkin C, DeMeulemeester C, MacLean H, Doja H. Neurophobia inception: A Study of Trainees' Perceptions of Neurology Education. Can J Neurol Sci. 2014; 41: 421-29.
4. Pakpoor J, Handel AE, Disanto G, Davenport RJ, Giovannoni G, Ramagopalan SV. National survey of UK medical students on the perception of neurology. BMC Med Ed. 2014: 14: 225-29.

5. Zinchuk AV, Flanagan EP, Tubridy NJ, Miller WA, McCullough LD. Attitudes of US medical trainees towards neurology education: "Neurophobia" - a global issue. BMC Med Educ. 2010, 10:49-55.

6. Fuller GN. Neurophilia: a fascination for Neurology - a new syndrome. Pract Neurol. 2012; 12: 276-78.

7. Humbert KA, Chang BS. In the beginning: How medical students choose (or do not choose) Neurology. Ann Neurol. 2014; 75(4): 487-89.

8. Sandelowski M. What's in a name? Qualitative description revisited. Res in Nursing and Health. 2010;33:77-84.

9. Ahmed Z, Lakhan SE, Tepper D. Opinion and special articles: Neurology training: To pursue or not to pursue a fellowship. Neurology. 2014; 83(4): e53-55.

10. Dewey RB, Agostini M. Attitudes and performance of third- vs. fourth-year Neurology clerkship students. Arch Neurol. 2010; 67(5): 548-51. 